Article

\title{
Effect of Contact Plug Deposition Conditions on Junction Leakage and Contact Resistance in Multilevel CMOS Logic Interconnection Device
}

\author{
Yinhua Cui ${ }^{1,+}$, Jeong Yeul Jeong ${ }^{2,+}$, Yuan Gao ${ }^{1}$ and Sung Gyu Pyo ${ }^{1, *(1)}$ \\ 1 School of Integrative Engineering, Chung-Ang University, Seoul 06974, Korea; yinhua0822@gmail.com (Y.C.); \\ gaoyuan4025@gmail.com (Y.G.) \\ 2 Process Development Center, Magnachip Semiconductor, Seoul 15213, Korea; trinitysg@naver.com \\ * Correspondence: sgpyo@cau.ac.kr \\ $\dagger$ These two authors contributed equally to this work.
}

Received: 29 November 2019; Accepted: 6 February 2020; Published: 6 February 2020

\begin{abstract}
Here, we developed the optimal conditions in terms of physical and electrical characteristics of the barrier and tungsten (W) deposition process of a contact module, which is the segment connecting the device and the multi-layer metallization (MLM) metal line in the development of $100 \mathrm{~nm}$-class logic devices. To confirm its applicability to the logic contact of barrier and $\mathrm{W}$ films, a contact hole was formed, first to check the bottom coverage and the filling status of each film, then to check the electrical resistance and leakage characteristics to analyze the optimal conditions. At an aspect ratio of 3.89:1, ionized metal plasma (IMP) Ti had a bottom coverage of $40.9 \%$ and chemical vapor deposition (CVD) titanium nitride (TiN) of $76.2 \%$, confirming that it was possible to apply the process to $100 \mathrm{~nm}$ logic contacts. W filling was confirmed, and a salicide etching rate (using Radio Frequency (RF) etch) of 13-18 $\AA / \mathrm{s}$ at a 3.53:1 aspect ratio was applied. The etching rate on the thermal oxide plate was $9 \AA / \mathrm{s}$. As the RF etch amount increased from $50-100 \AA$, the P active resistance increased by $0.5-1 \Omega$. The resistance also increased as the amount of IMP Ti deposition increased to $300 \AA$. A measurement of the borderless contact junction leakage current indicated that the current in the P $+\mathrm{N}$ well increased by more than an order of magnitude when IMP Ti $250 \AA$ A or more was deposited. The contact resistance value was $0.5 \Omega$. An AC bias improved the IMP Ti deposition rate by $10 \%$ in bottom coverage, but there was no significant difference in contact resistance. In the case of applying IMP TiN, the overall contact resistance decreased to $2 \Omega$ compared to CVD TiN, but the distribution characteristics were poor. The best results were obtained under the conditions of RF etch $50 \AA$, IMP Ti $200 \AA$, and CVD TiN $2 \times 50 \AA$.
\end{abstract}

Keywords: junction leakage; contact resistance; contact metallization

\section{Introduction}

In this report, we sought to find the ideal conditions and device characteristics based on the process splits that were performed for the contact plug process setup of $0.15 \mu \mathrm{m}$ logic devices. The contact design rule for a $0.15 \mu \mathrm{m}$ logic device requires a hole size of $0.18 \mu \mathrm{m}$ and an interlayer dielectric (ILD) thickness of $7500 \AA$, with an aspect ratio of 4.16:1, making it more fragile than the 3.69:1 $(0.23 \mu \mathrm{m}$, $8500 \AA$ A) of a $0.18 \mu \mathrm{m}$ logic device. As a result, a borderless contact (BLC) structure was adopted. BLC nitride was used as an etch stop layer and cobalt (Co) silicide [1] was applied to the salicide process [2].

As mentioned above, the contact plug design [3] reduction of the $0.15 \mu \mathrm{m}$ logic device was the main change compared to the $0.18 \mu \mathrm{m}$ logic device, and this was set up based on the possibility of process change [4]. We examined the physical and electrical characteristics of pre-cleaning, adhesion 
layer, barrier layer, etc. currently applied to logic devices, and judged whether they were appropriate here, before selecting the optimal contact plug conditions. As with the via plug, the tungsten (W) plug process [5] was applied to the contact plug, and the barrier film and adhesion layer were applied to Metal Organic Chemical Vapor Deposition (MOCVD) TiN [6] and ionized metal plasma (IMP) Ti, respectively $[7,8]$. Currently, the Ti deposition process that can be applied in terms of bottom coverage utilizes only the IMP method, while in the case of the TiN deposition process, MOCVD [9] TiN, which has excellent bottom coverage characteristics [10], is applied. In addition, Radio Frequency (RF) etch cleaning was adopted for the pre-cleaning process, according to the BLC structure [11,12]. Recently, the trend of standard CMOS processes is to apply Co silicide or Ni silicide in 10nm contact process and copper contact in devices requiring high speed. Future research is also underway to apply nanowires and graphene [13]. However, W is applied to memory devices that do not require high speed, and optimized process conditions are applied according to ILD thickness and contact profile. Therefore, it is important to note that the contact profiles formed through photo lithography and etch processes of all companies are very different in terms of process integration. Constant process development is still in progress. Therefore, in this study, we also established contact plug optimization conditions based on contact resistance and junction leakage characteristics in order to establish optimized contact plug conditions according to RF etching and deposition characteristics according to the given process integration profile.

This report, therefore, is focused on RF pre-cleaning [14], IMP Ti, chemical vapor deposition (CVD) TiN, and CVD W [15] $0.15 \mu \mathrm{m}$ logic devices based on contact resistance, leakage, etc. after checking basic properties such as the bottom coverage and $W$ filling status of each film. This study attempts to examine and select the optimal conditions for this contact plug process [16].

\section{Experimental Procedure}

The equipment used for depositing the barrier film before the $\mathrm{W}$ deposition was the C-03-12 (Endura, AMAT) of the FAB 4 line. This equipment comprises the RF etch (pre-clean), IMP Ti, IMP TiN, CVD TiN chambers, and it is possible to continuously process RF etch-IMP Ti-CVD TiN (or IMP TiN) without an air break. Table 1 shows the specific resistance of each film and Table 2 shows the deposition conditions. The resistivity was obtained by depositing $5000 \AA$ of PETEOS, $200 \AA$ of IMP Ti, $100 \AA$ of CVD TiN, and $300 \AA$ of IMP TiN on the bare wafer. RF etch conditions were performed with RF power at $400 \mathrm{~W}$, RF second power at $275 \mathrm{~W}$, and Ar gas $10 \mathrm{sccm}$. CVD tungsten deposition was performed using the Concept- 1 (Novellus). The air flow of deposition conditions were $\mathrm{SiH}_{4}, 0.025 \mathrm{slm}$; $\mathrm{H}_{2}, 6 \mathrm{slm}$; WF 6, $0.28 \mathrm{slm}$; temp, $395{ }^{\circ} \mathrm{C}$, and $\mathrm{SiH}_{4}$ reduction time of the $\mathrm{W}$ seed formation step set to $12 \mathrm{~s}$. Under these conditions, the resistivity of tungsten was measured by determining the Rs using an omnimap after depositing about $3800 \AA$ of tungsten after measuring the resistivity of the barrier film. Step coverage and filling of the CVD TiN, IMP TiN, and CVD W thin films were analyzed using SEM and TEM. Due to the reduction of the contact hole size, it was difficult to obtain the correct cutting surface in general specimen preparation, so the cross section was checked again using the Precision Etching Coating System (PECS) [17]. Existing published paper [18] support this paper.

Table 1. Sheet resistance $(R s)$ and specific resistance value $(\rho)$ for each film.

\begin{tabular}{cccc}
\hline & IMP Ti & CVD TiN & IMP TiN \\
\hline Average Rs $\left(\Omega / \mathrm{cm}^{2}\right)$ & 39.9 & 302.05 & 29.06 \\
\hline Unif. $(\%)$ & 4.99 & 3.55 & 9.05 \\
\hline TEM thickness $($ center, $\AA$ ) & 195 & 100 & 345 \\
\hline Rs (center, $\left.\Omega / \mathrm{cm}^{2}\right)$ & 37.5 & 280.8 & 24.73 \\
\hline Specific Resistance $(\mu \Omega \cdot \mathrm{cm})$ & $\sim 73$ & $\sim 280$ & $\sim 85$ \\
\hline Stress $\left(\right.$ dyne $\left./ \mathrm{cm}^{2}\right)$ & $-2.142 \times 10^{9}$ & $-4.788 \times 10^{9}$ & $-6.762 \times 10^{9}$ \\
\hline
\end{tabular}


Table 2. Deposition conditions for each film.

\begin{tabular}{rcccccc}
\hline \multirow{2}{*}{ IMP Ti } & DC power & RF power & AC bias & Ar & \\
\cline { 2 - 6 } & $2250 \mathrm{~W}$ & $2750 \mathrm{~W}$ & $0 \mathrm{~W}$ & $56 \mathrm{sccm}$ & \\
\hline \multirow{2}{*}{ CVD TiN } & \multicolumn{7}{c}{ DEP } & \multicolumn{2}{c}{ Plasma Treat } \\
\cline { 2 - 6 } & Pressure & TEMP & He carr & Pressure & RF power & TEMP \\
\cline { 2 - 6 } & 1.5 Torr & $450{ }^{\circ} \mathrm{C}$ & $225 \mathrm{sccm}$ & $1.3 \mathrm{Torr}$ & $750 \mathrm{~W}$ & $450{ }^{\circ} \mathrm{C}$ \\
\hline \multirow{2}{*}{ IMP TiN } & DC power & RF power & AC bias & Ar & N2 & \\
\cline { 2 - 6 } & $4000 \mathrm{~W}$ & $2500 \mathrm{~W}$ & $0 \mathrm{~W}$ & $25 \mathrm{sccm}$ & $28 \mathrm{sccm}$ & \\
\hline
\end{tabular}

\section{Results and Discussion}

As shown in Table 1, the uniformity of the IMP process tended to be high, a tendency known as a characteristic of the IMP process rather than a problem of the deposition conditions. CVD TiN was deposited at $2 \times 50 \AA$ for a total of $100 \AA$ and IMP TiN was deposited without an AC bias (as with IMP Ti). The CVD TiN $2 \times 50$ process is a two-step process of film deposition and in situ plasma post-treatment. The reason why the IMP TiN process was compared with CVD TiN was to examine the possibility of optimizing an integrated process because of IMP TiN's advantages and its low resistivity in terms of throughput [19].

First, each film was deposited using wafer defining contact holes to confirm the bottom coverage of IMP Ti and CVD TiN. The contact holes were defined in accordance with the $150 \mathrm{~nm}$-class logic contact design rules [20,21]. Figure 1 shows the bottom coverage of IMP Ti and CVD TiN. The bottom CD of the contact hole implemented on the test wafer with TEM was about $0.185 \mu \mathrm{m}$ and the ILD thickness was about $7200 \AA$, while the aspect ratio was calculated to be about 3.89:1. As a result of measuring the deposition amount at the hole bottom of each film, it was confirmed that about $90 \AA$ was deposited on the contact hole bottom when IMP Ti $220 \AA$ was deposited, and about $80 \AA$ was deposited when CVD TiN 105 was deposited. In IMP Ti was about 40.9\%, CVD TiN was about $76.2 \%$. From these results, the bottom coverage in terms of the aspect ratio in the design contact hole is considered to be good, and there was no problem in applying it to the $150 \mathrm{~nm}$ logic device process integration process $[22,23]$. The electrical properties such as contact resistance were measured, in order to verify this.

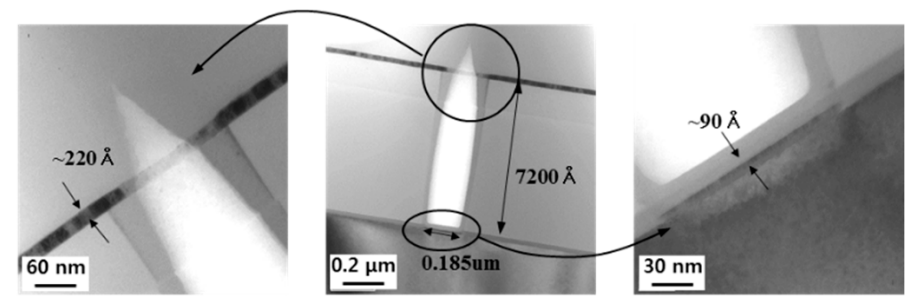

(a) IMP Ti 200

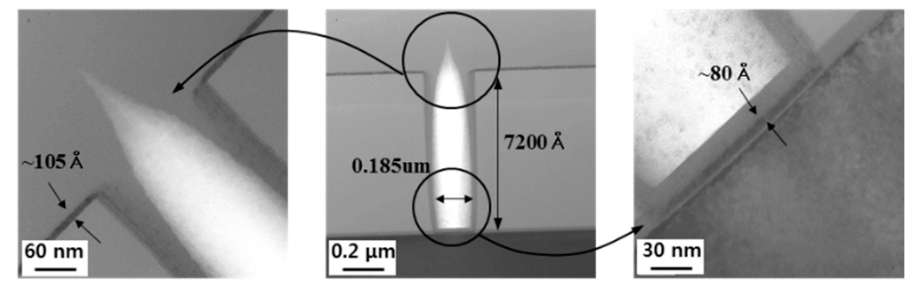

(b) CVD TiN 2X50

Figure 1. TEM image of ionized metal plasma (IMP) Ti and chemical vapor deposition (CVD) TiN at an aspect ratio of 3.89: 1. (a) IMP Ti 200. (b) CVD TiN $2 \times 50$ (unit: $⿱$ ). 
To confirm the $\mathrm{W}$ filling state in the contact hole, CVD tungsten deposition proceeded for $12 \mathrm{~s}$ of SiH4 [24] reduction time, a W seed formation step [25,26]. Under the same conditions as in the measurement of the resistivity of the barrier film, the resistivity calculated after deposition of tungsten $3800 \AA$ was about $11.5 \Omega \cdot \mathrm{cm}$. Figure 2 shows an SEM image of the contact plug cross section. As shown in the figure, the tungsten filling of the contact hole was confirmed, and it is thought that the tungsten could be filled to ILD $6700 \AA$, even with a contact hole size of $0.14 \mu \mathrm{m}$, under the current deposition conditions. Considering the $0.14 \mu \mathrm{m}$ hole size, it was confirmed that there was no problem in filling the contact hole of $150 \mathrm{~nm}$-class logic devices. Interlayer dielectric (ILD) layers of $150 \mathrm{~nm}$-class logic devices are stacked from the bottom in the order of nitride-BPSG (borophosphosilicate glass) -PETEOS (plasma enhanced tetraethylorthosilicate layers) [26,27]. Due to this structure, there is a problem in applying pre-cleaning to wet clean the substrate before barrier deposition [28]. That is, there are problems of deformation of the hole profile due to the selective etching ratio of each film and problems of characteristic leakage deterioration in the BLC structure [29]. As a result, a pre-cleaning method using an RF etch is used. However, RF etch cleaning has a high salicide etching rate [30], and the salicide etching amount at the hole bottom was confirmed by the RF etch quantity. The test wafer had a contact hole height of about $6700 \AA$ and a bottom CD of about $0.19 \mu \mathrm{m}$. The aspect ratio was about 3.53. The deposition thickness of BLC nitride was $200 \AA$ and the salicide thickness was about 350 400 A. The RF etch conditions were RF power at $400 \mathrm{~W}$, RF second power at $275 \mathrm{~W}, \mathrm{Ar}$ gas $10 \mathrm{sccm}$, and were split into $50 \AA, 100 \AA$, and $150 \AA$ layers, respectively, based on the thermal oxide on the plate. After coating, cross-sectional SEM observations made it easy to check the salicide thickness. The results are shown in Figure 3.
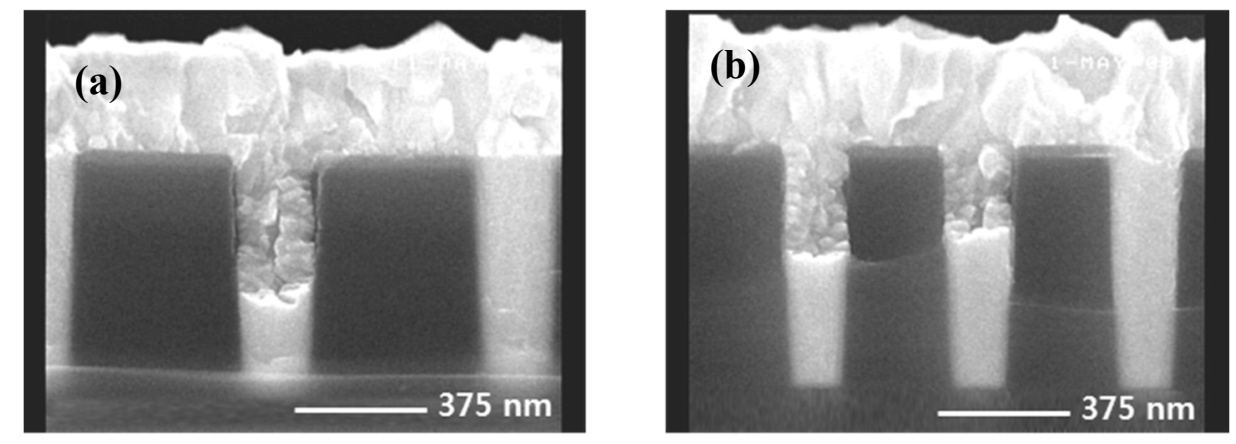

Figure 2. SEM image of cross section after tungsten deposition of contact hole size (a) $0.16 \mu \mathrm{m}$ with interlayer dielectric (ILD) thickness $6700 \AA$ and (b) $0.14 \mu \mathrm{m}$ with ILD thickness $6700 \AA$.

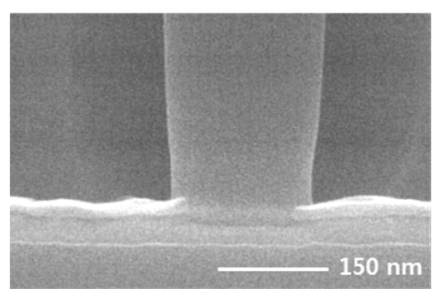

(a) RF etch $50 \AA$

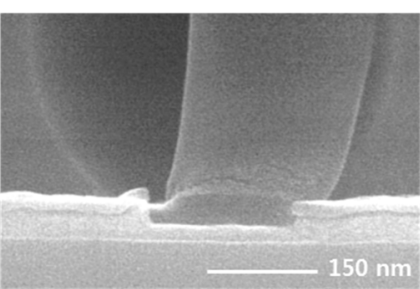

(b) RF etch $100 \AA$

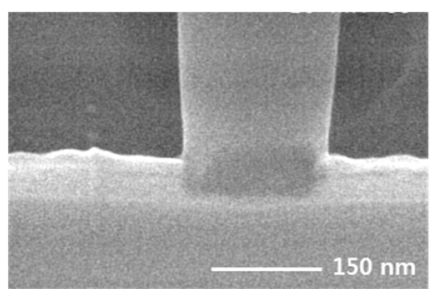

(c) RF etch $150 \AA$

Figure 3. Cross-sectional SEM of etching amount of Co salicide according to Radio Frequency (RF) etch amount. (a) RF etch $50 \AA$. (b) RF etch $100 \AA$. (c) RF etch $150 \AA$.

As shown in Figure 3, the amount of salicide remaining at the bottom of each hole was measured at about $250 \AA, 200 \AA$, and $130 \AA$ as the etch amount increased, and the amount of salicide was measured at about $100 \AA, 150 \AA$, and $220 \AA$, respectively. It is difficult to accurately compare the thicknesses because salicide formation varies locally, but the salicide etch rate at an aspect ratio of 3.53 was calculated to be about $13-18 \AA /$ s, versus the RF etch rate of $9 \AA /$ s on the plate. 
In order to evaluate the contact resistance characteristics according to the process conditions, IMP Ti and CVD TiN conditions were fixed, RF etch was fixed at $50 \AA, 70 \AA, 100 \AA$, RF etch and CVD TiN conditions were fixed, and IMP Ti thickness was $150 \AA, 200 \AA, 250 \AA$, 300, $\AA$ respectively.

Figure 4 shows the results of contact resistance by experimental conditions to understand the contact resistance and leakage characteristics according to the barrier deposition scheme. As can be seen, $\mathrm{N}$ active resistance shows poor results, while $\mathrm{P}$ active resistance shows 8-12 $\Omega$ for chain resistance, and 6-8 $\Omega$ for kelvin resistance, without any difference between the splits. The reason for this $\mathrm{N}$ active resistance was found to be due to the abnormal oxidation phenomenon on the $\mathrm{N}$ active side of the salicide. Specimens were treated with a buffered oxide etch (BOE) [31] process for $15 \mathrm{~s}$ after cross section cutting and observed by cross section using SEM (Figure 5). A trace of oxide-like material was etched off just below the contact hole, which may have led to an increase in resistance. In the P active area, this phenomenon did not occur [32], so the contact resistance comparison was made only through the $P$ active area [33]. The resistance and leakage values in the wafer that was processed after the salicide process had stabilized, were compared again. As for the P etch resistance, we found that as the amount of RF etch increased from 50 to $100 \AA$, the resistance also increased by about $0.5-1.0 \Omega$, though the distribution tended to get worse [34]. However, in the case of IMP Ti $150 \AA$, while the distribution of kelvin resistance deteriorated, the chain pattern was similar to those under other conditions.
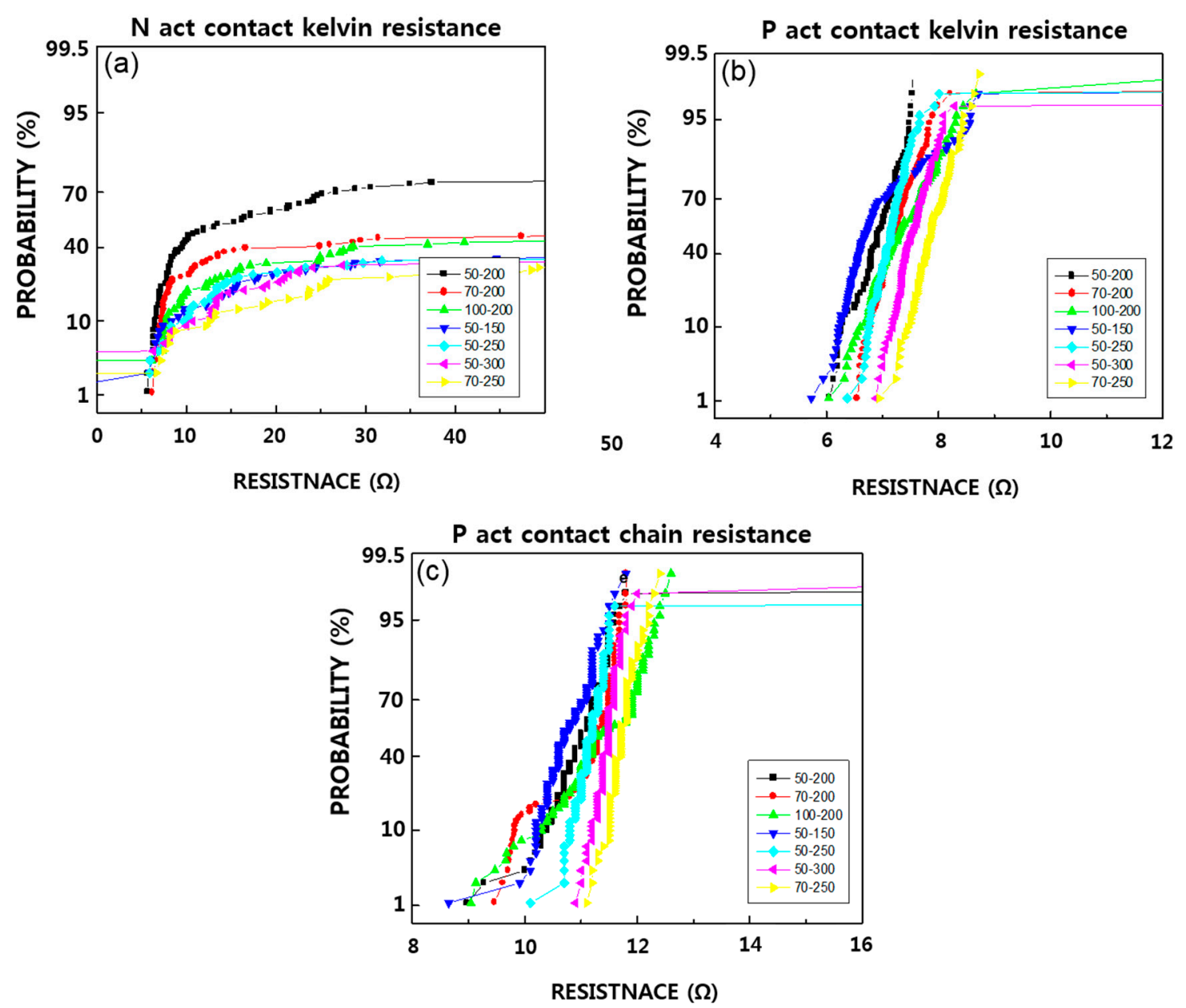

Figure 4. Result of (a) $\mathrm{N}$ act kelvin, (b) P act kelvin, (c) P act chain contact resistance by process conditions (unit: $\AA$ ). 




Figure 5. Cross section SEM image of specimens treated with a buffered oxide etch (BOE) process.

Figure 6 shows the P active BLC contact resistance values by split. Overall, there was no condition showing a bad resistance value. However, as with the kelvin resistance and the chain resistance, the resistance increase was 1-1.5 $\Omega$ as the RF etch quantity and IMP Ti deposition thickness were increased.

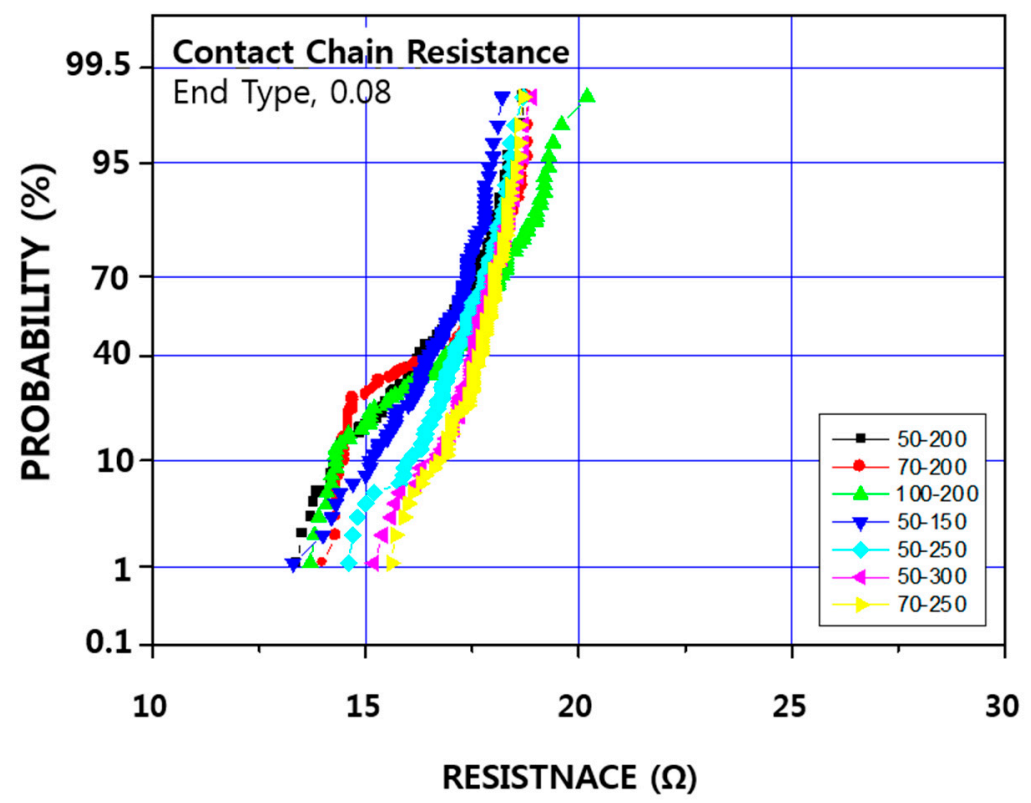

Figure 6. Active BLC contact resistance according to RF etch amount and IMP Ti deposition thickness. (unit: ^̊).

Figure 7 shows contact $\mathrm{P}+\mathrm{N}$ BLC leakage according to the RF etching amount and IMP Ti deposition thickness. In general, the leakage characteristics were poor, especially when the IMP Ti deposition thickness was more than $250 \AA$, the difference was more by as much as an order of magnitude. There were no significant differences in the other splits, and there was no difference between the end type and the peri type. Based on the above results, $\mathrm{P}$ active contact leakage characteristics of IMP Ti thickness of $250 \AA$ or more are difficult to assume in terms of leakage, though the lower the RF etch and IMP Ti thickness, the better the resistance characteristics [35]. 
(a)

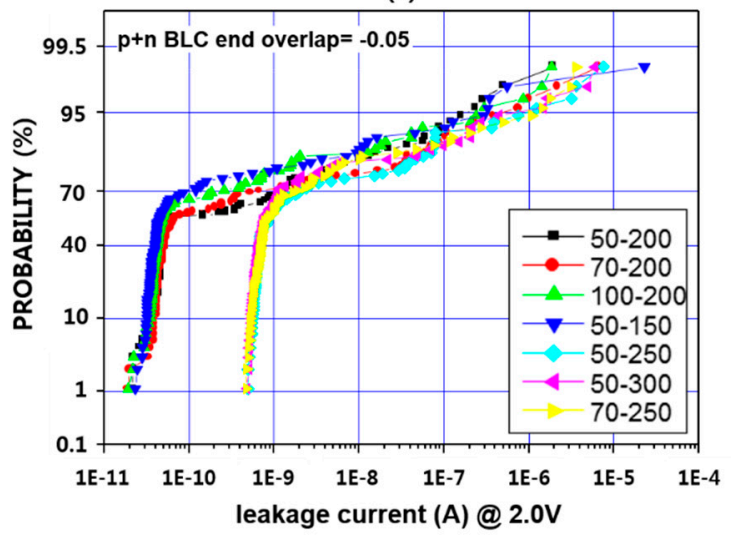

(b)

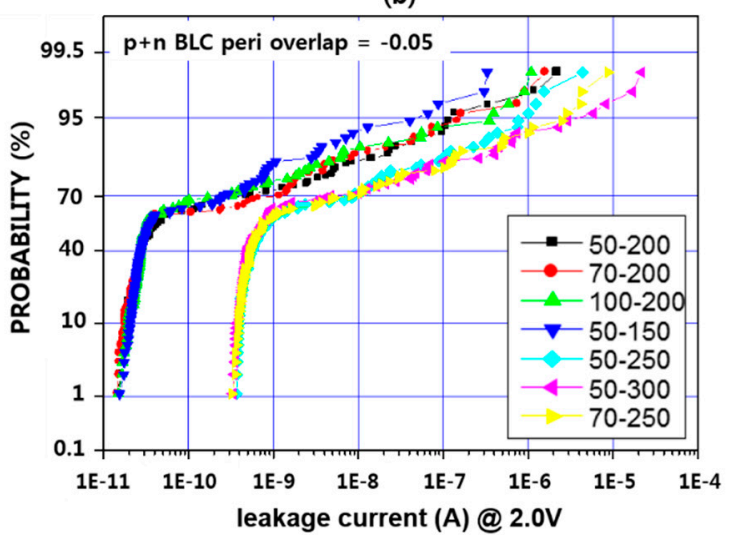

Figure 7. Contact $\mathrm{P}+\mathrm{N}$ BLC leakage at overlap -0.05 according to RF etch amount and IMP Ti deposition thickness. (a) end type (b) peri type (unit: $\AA$ ).

Based on the above results, the RF etch was conducted at $50 \AA, 30 \AA$, and IMP Ti at $200 \AA$ and $150 \AA$, respectively, and IMP TiN was applied to compare to the process proficiency of CVD TiN. Furthermore, to evaluate the damage caused by the AC bias on the IMP Ti deposition, the conditions of deposition by applying an AC bias of $200 \mathrm{~W}$ were also performed. The contact kelvin resistance is shown in Figure 8 and the chain resistance in Figure 9. The kelvin resistance was $6-8 \Omega$ on the active side, and 5-7 $\Omega$ on the poly side, and the chain resistance ranged from 9-11 $\Omega$ on the active side, and 8-10 $\Omega$ on the poly side. Compared to the poly side, the overall contact resistance was about $0.5 \Omega$ [36]. According to the experimental conditions, with the RF etch and IMP Ti reduced to $30 \AA$ and $150 \AA$ respectively, this tended to decrease the contact resistance by about $0.5 \Omega$, but with RF etch $50 \AA$ and IMP Ti $200 \AA$, the results showed a stable distribution without deterioration of the contact resistance value.
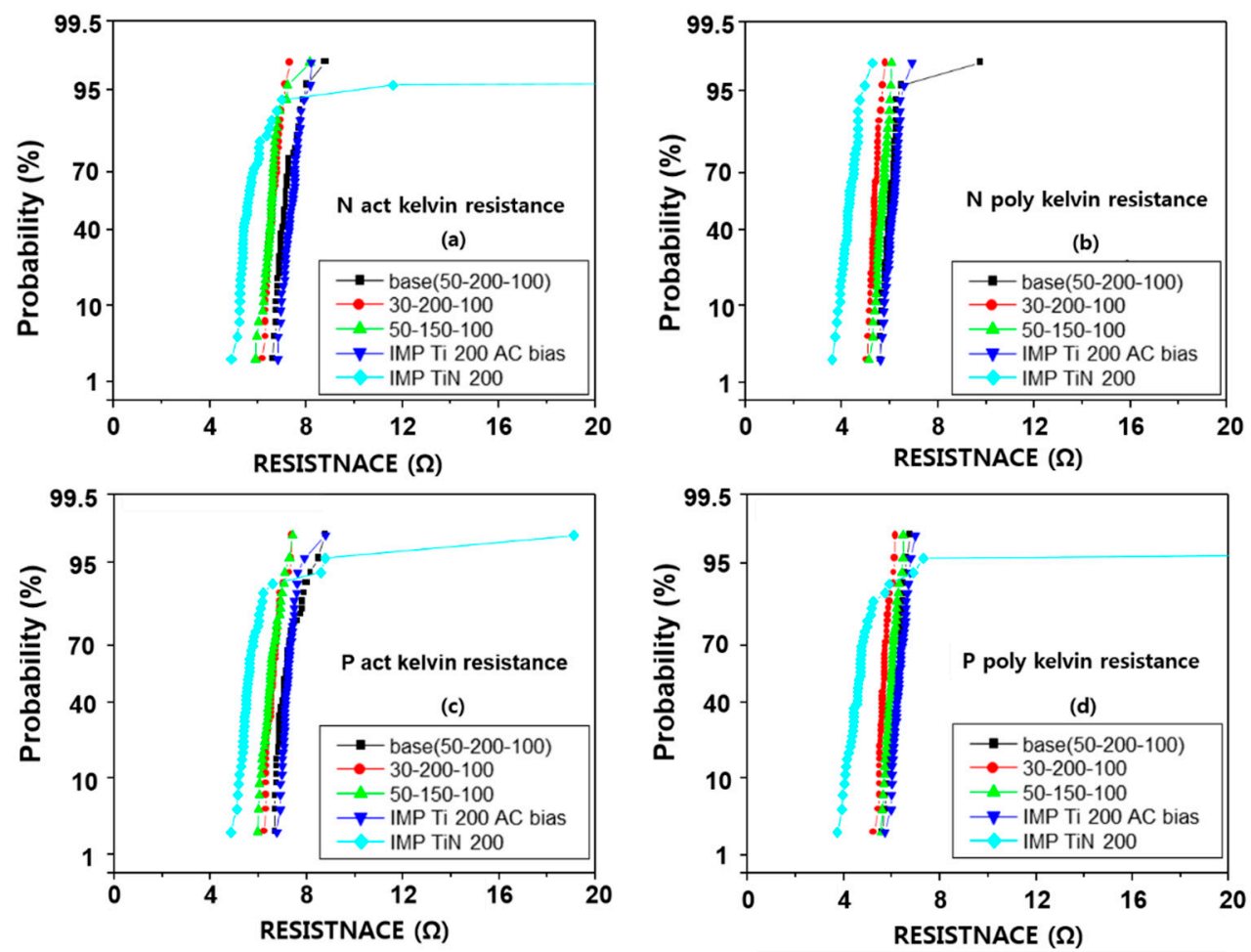

Figure 8. Electrical properties of (a) N act kelvin, (b) N poly kelvin, (c) P act kelvin, and (d) P poly contact resistance (Kelvin type) (unit: $\AA$ ). 



Figure 9. Electrical properties of (a) N act chain, (b) N poly chain, (c) P act chain, and (d) P poly chain contact resistance (chain type) (unit: $\AA$ ).

In the case of IMP Ti deposition, the split with AC bias fixed at $200 \AA$ of IMP Ti deposition thickness, was about $51.2 \%$. In terms of bottom coverage, the effect was about $10 \%$ better than that of $40.9 \%$ in the 'no bias' condition. However, as shown in Figures 8 and 9, in terms of contact resistance, the change of resistance tends to increase slightly or not at all, when an AC bias is used [37].

In the case of depositing IMP TiN $200 \mu$ s instead of CVD TiN $100 \mu \mathrm{s}$, the kelvin resistance [38] was about 1.5-2 $\Omega$. However, unlike CVD TiN, which showed an even distribution of resistance, the resistance distribution of $10-20 \%$ tends to reduce. This phenomenon is different from that shown in the via resistance [39], and it seems that there is a problem in applying IMP TiN to the contact barrier [40]. In the case of CVD TiN, as shown in the via, it was confirmed that the stable distribution was shown in the $2 \times 50$ condition without much problem. In terms of leakage current distribution, the RF etch $50 \AA-I M P$ Ti $200 \AA-C V D$ TiN $2 \times 50 \AA$ seems to be the best condition. It seems that there is little effect and the BLC leakage [29] current is expected to increase when IMP Ti thickness is over $250 \AA$. The increase in BLC leakage current with increasing IMP Ti thickness is expected due to the deposited Ti reacting with active by diffusing salicide through the rapid thermal process (RTP).

\section{Summary}

Based on the physical and electrical characteristics measured, the RF etch $50 \AA$, IMP Ti $200 \AA$, CVD TiN $2 \times 50 \AA$, and CVD W $3800 \AA$ conditions are not considered to be optimal for the $100 \mathrm{~nm}$ contact plug. With the RF etch and IMP Ti thickness lowered to $30 \AA$ and $150 \AA$, respectively, the contact resistance could be further reduced. However, the difference was $0.5 \Omega$. There was no significant effect in terms of resistance distribution or BLC leakage. On the other hand, the RF etch is expected 
to reduce the amount to 30, resulting in sufficient contact hole floor cleaning effect and difficulty in securing process margin. Although IMP TiN showed an improved effect in terms of contact resistance, it is difficult to apply due to the poor resistance distribution, though it may be applicable if resistance distribution improvements are made in the future. At an aspect ratio of 3.89:1, IMP Ti bottom coverage of $40.9 \%$, and CVD TiN bottom coverage of $76.2 \%$ was confirmed, $\mathrm{W}$ filling was confirmed. The salicide etching rate by RF etch was about $13-18 \AA$ at 3.53:1 aspect ratio. At this stage, the etching rate of the thermal oxide plate was $9 \AA / \mathrm{s}$. As the RF etch amount increased from 50 to $100 \AA$, the contact resistance of $P$ active also increased about $0.5-1 \Omega$, and the resistance increased slightly too as the IMP Ti deposition increased to $300 \AA$. As a result of the BLC junction leakage current measurement, a current increase of about an order of magnitude was observed in the P + N well when IMP Ti $250 \AA$ or more was deposited. In terms of the RF etch quantity and IMP Ti deposition thickness, the contact resistance value was reduced by about $0.5 \Omega$ at $30 \AA$ with the RF etch $50 \AA$ and $150 \AA$ than with IMP Ti $200 \AA$. In the case of IMP Ti deposition, the effect of an AC bias showed a 10\% improvement in bottom coverage. There was no significant difference in contact resistance, but rather a slight increase. The overall contact resistance of IMP TiN decreased by $2 \Omega$ compared to CVD TiN, but the distribution characteristics were poor. The best results were obtained under the conditions of RF etch $50 \AA$, IMP Ti $200 \AA$, and CVD TiN $2 \times 50 \AA$.

Author Contributions: Conceptualization, Y.C. and J.Y.J.; methodology, J.Y.J.; resources, Y.C. and Y.G.; software, Y.G.; validation, S.G.P.; writing—original draft, S.G.P.; writing—review and editing, Y.C. and S.G.P. All authors have read and agreed to the published version of the manuscript.

Funding: This research was supported by the Basic Science Research Program through the National Research Foundation of Korea (NRF) funded by the Ministry of Education, Science and Technology (NRF-2019R1A2C1007670).

Acknowledgments: The author would like to thank Magnachip members for their assistance and discussions.

Conflicts of Interest: The authors declare no conflict of interest.

\section{References}

1. Ekström, M.; Hou, S.; Elahipanah, H.; Salemi, A.; Östling, M.; Zetterling, C.M. Low temperature Ni-Al ohmic contacts to $\mathrm{p}-\mathrm{TYPE} 4 \mathrm{H}-\mathrm{SiC}$ using semi-salicide processing. In Proceedings of the Materials Science Forum, Shanghai, China, 11-12 March 2018; pp. 389-392.

2. Wu, J.; Li, C.; Wang, H.; Li, J.; Zheng, L. Modelling of initial fast charge loss mechanism for logic embedded non-volatile memories. Microelectron. Reliab. 2017, 76, 174-177. [CrossRef]

3. Roos, M.M.; Huffert, T.; Puchinger, A.; Strehle, S. Rapid Micro-Nano-Integration of Single Silicon Nanowires in 2D-Sensor Arrays using Automated Software Tools. In Proceedings of the Micro-Nano-Integration, 7th GMM-Workshop, Dortmund, Germany, 22-23 October 2018; pp. 1-5.

4. Ireland, P.J. High aspect ratio contacts: A review of the current tungsten plug process. Thin Solid Film 1997, 304, 1-12. [CrossRef]

5. Fan, R.; Chen, H.; Wang, K.; Liu, Z.; Long, Y.; Ni, Q.; Gu, X. The detection and investigation of Tungsten-plug voids by electron-beam inspection. In Proceedings of the 2018 China Semiconductor Technology International Conference (CSTIC), Shanghai, China, 11-12 March 2018; pp. 1-3.

6. Xiang, W.; Liu, Y.; Zhang, J. Influence of Microstructure on the Electrical Properties of Heteroepitaxial TiN Films. Electron. Mater. Lett. 2018, 14, 314-318. [CrossRef]

7. Okada, M.; Terada, S.; Miura, T.; Iwai, Y.; Takazawa, T.; Kataoka, Y.; Kihara, T.; Otsu, M. Fundamental burnishing characteristics of Ni-based alloy using coated carbide tool. Procedia. Manuf. 2018, 15, 1278-1283. [CrossRef]

8. Wang, Y.; Zhang, L.; Su, C.; Xiao, H.; Lv, S.; Zhang, F.; Sui, Q.; Jia, L.; Jiang, M. Direct Observation of Monolayer MoS2 Prepared by CVD Using In-Situ Differential Reflectance Spectroscopy. Nanomaterials 2019, 9, 1640. [CrossRef] [PubMed]

9. Cun, H.; Macha, M.; Kim, H.; Liu, K.; Zhao, Y.; LaGrange, T.; Kis, A.; Radenovic, A. Wafer-scale MOCVD growth of monolayer MoS2 on sapphire and SiO2. Nano Res. 2019, 12, 2646-2652. [CrossRef] 
10. Schulze, S.; Wolansky, D.; Katzer, J.; Schubert, M.A.; Costina, I.; Mai, A. Impact of TiN Barrier Layer on Contact Resistance of Tungsten Filled Vias. IEEE Trans. Semicond. Manuf. 2018, 31, 528-534. [CrossRef]

11. Liao, H.; Lee, P.S.; Goh, L.N.L.; Liu, H.; Sudijono, J.L.; Elgin, Q.; Sanford, C. The impact of etch-stop layer for borderless contacts on deep submicron CMOS device performance-A comparative study. Thin Solid Film. 2004, 462, 29-33. [CrossRef]

12. Tripathi, K.P.; Durbach, S.; Coville, J.N. Synthesis of Multi-Walled Carbon Nanotubes from Plastic Waste Using a Stainless-Steel CVD Reactor as Catalyst. Nanomaterials 2017, 7, 284. [CrossRef]

13. Liu, Y.; Song, Z.; Yuan, S.; Xu, L.; Xin, Y.; Duan, M.; Yao, S.; Yang, Y.; Xia, Z. Enhanced Ultra-violet Photodetection Based on a Heterojunction Consisted of ZnO Nanowires and Single-Layer Graphene on Silicon Substrate. Electron. Mater. Lett. 2020, 16, 81-88. [CrossRef]

14. Yadav, A.B.; Parvathi, P.V.L.; Ramana, P.V.; Thabassum, R. Zero bias UV detection and precursor effect on properties of $\mathrm{ZnO}$ nanorods grown by hydrothermal method on $\mathrm{SiO} 2 / \mathrm{p}-\mathrm{Si}$ substrate. Thin Solid Film. 2019, 685, 343-352. [CrossRef]

15. Choi, D.; Barmak, K. On the potential of tungsten as next-generation semiconductor interconnects. Electron. Mater. Lett. 2017, 13, 449-456. [CrossRef]

16. Ieong, M.; Narayanan, V.; Singh, D.; Topol, A.; Chan, V.; Ren, Z. Transistor scaling with novel materials. Mater. Today 2006, 9, 26-31. [CrossRef]

17. Kim, J.S.; Ahn, J. Mask Materials and Designs for Extreme Ultra Violet Lithography. Electron. Mater. Lett. 2018, 14, 533-547. [CrossRef]

18. Cui, Y.; Jeong, J.Y.; Gao, Y.; Pyo, S.G. Process Optimization of Via Plug Multilevel Interconnections in CMOS Logic Devices. Micromachines 2019, 11,32. [CrossRef] [PubMed]

19. Dixit, G.A.; Hsu, W.Y.; Konecni, A.J.; Krishnan, S.; Luttmer, J.D.; Havemann, R.H.; Forster, J.; Yao, G.D.; Narasimhan, M.; Xu, Z. Ion metal plasma (IMP) deposited titanium liners for 0.25/0.18/spl mu/m multilevel interconnections. In Proceedings of the International Electron Devices Meeting, San Francisco, CA, USA, 8-11 December 1996; pp. 357-360.

20. Lee, S.-Y.; Chen, H.-W.; Shen, C.-H.; Kuo, P.-Y.; Chung, C.-C.; Huang, Y.-E.; Chen, H.-Y.; Chao, T.-S. Experimental Demonstration of Performance Enhancement of MFMIS and MFIS for 5-nm× 12.5-nm Poly-Si Nanowire Gate-All-Around Negative Capacitance FETs Featuring Seed-Layer and PMA-Free Process. In Proceedings of the 2019 Silicon Nanoelectronics Workshop (SNW), San Francisco, CA, USA, 8-11 December 1996; pp. 1-2.

21. Riverola, M.; Torres, F.; Uranga, A.; Barniol, N. High Performance Seesaw Torsional CMOS-MEMS Relay Using Tungsten VIA Layer. Micromachines 2018, 9, 579. [CrossRef]

22. Choy, K.L. CVD of superlattice films and their applications. In Chemical Vapour Deposition (CVD) Advances, Technology and Applications, 1st ed.; CRC Press Taylor \& Francis Group: Boca Raton, FL, USA, 2019; pp. $273-277$.

23. Li, Y.; Jiang, C.; Wang, Z.; Luo, P. Experimental Study on Reaction Characteristics of PTFE/Ti/W Energetic Materials under Explosive Loading. Materials 2016, 9, 936. [CrossRef]

24. Kojima, T.; Toko, S.; Tanaka, K.; Seo, H.; Itagaki, N.; Koga, K.; Shiratani, M. Effects of Gas Velocity on Deposition Rate and Amount of Cluster Incorporation into a-Si:H Films Fabricated by $\mathrm{SiH}_{4}$ Plasma Chemical Vapor Deposition. Plasma Fusion Res. 2018, 13, 1406082. [CrossRef]

25. Liu, Z.; Fu, H.; Hunegnaw, S.; Wang, J.; Merschky, M.; Magaya, T.; Mieno, A.; Shorey, A.; Kuramochi, S.; Akazawa, M. Electroless and electrolytic copper plating of glass interposer combined with metal oxide adhesion layer for manufacturing 3D RF devices. In Proceedings of the 2016 IEEE 66th Electronic Components and Technology Conference (ECTC), Las Vegas, NV, USA, 31 May-3 June 2016; pp. 62-67.

26. Kim, H.; Yun, S.J.; Park, J.C.; Park, M.H.; Park, J.; Kim, K.K.; Lee, Y.H. Seed Growth of Tungsten Diselenide Nanotubes from Tungsten Oxides. Small 2015, 11, 2192-2199. [CrossRef]

27. Weiqiang, L.I.; Wang, Y.; Wee, K.S.; Zhang, F. ILD Interlaminar Strength Evaluation for WLCSP. In Proceedings of the 2018 20th International Conference on Electronic Materials and Packaging (EMAP) Clear Water Bay, Hong Kong, China, 17-20 December 2018; pp. 1-3.

28. Kang, S.; Kim, Y.; Moon, A.; Lee, S.; Kim, S.E.; Kim, S. Surface Planarization of Polymeric Interlayer Dielectrics for FOWLP Applications. In Proceedings of the 2018 IEEE 20th Electronics Packaging Technology Conference (EPTC), Singapore, 4-7 December 2018; pp. 882-885. 
29. Hao, M.; Wang, Q.; Jiang, L.; Feng, C.; Chen, C.; Wang, C.; Xiao, H.; Liu, F.; Xu, X.; Wang, X. Gate Leakage and Breakdown Characteristics of AlGaN/GaN High-Electron-Mobility Transistors with Fe Delta-Doped Buffer. Nanosci. Nanotechnol. Lett. 2018, 10, 185-189. [CrossRef]

30. Brainard, W.A.; Wheeler, D.R. An XPS study of the adherence of refractory carbide silicide and boride rf-sputtered wear-resistant coatings. J. Vac. Sci. Technol. 1978, 15, 1800-1805. [CrossRef]

31. Hartensveld, M.; Zhang, J. Monolithic Integration of GaN Nanowire Light-Emitting Diode With Field Effect Transistor. IEEE Electron. Device Lett. 2019, 40, 427-430. [CrossRef]

32. Tomita, R. A Study on Formation of High Resistivity Phases of Nickel Silicide at Small Area and Its Solution for Scaled CMOS Devices. Ph.D. Thesis, Interdisciplinary Graduate School of Science and Engineering, Tokyo Institute of Technology, Tokyo, Japan, 26 March 2013.

33. Mun, S.Y.; Shin, K.C.; Lee, S.S.; Kwak, J.S.; Jeong, J.Y.; Jeong, Y.H. Etch defect reduction using SF6/O2 plasma cleaning and optimizing etching recipe in photo resist masked gate poly silicon etch process. Jpn. J. Appl. Phys. 2005, 44, 4891. [CrossRef]

34. Jang, J.-S.; Park, S.-J.; Seong, T.-Y. Formation of low resistance Pt ohmic contacts to p-type GaN using two-step surface treatment. J. Vac. Sci. Technol. B Microelectron. Nanom. Struct. Process. Meas. Phenom. 1999, 17, 2667-2670. [CrossRef]

35. Li, Y.; Li, J.; Xu, L. Method of Calculating the Inductance Value of MEMS Suspended Inductors with Silicon Substrates. Micromachines 2018, 9, 604. [CrossRef] [PubMed]

36. Szutkowska, M.; Cygan, S.; Podsiadło, M.; Laszkiewicz-Łukasik, J.; Cyboroń, J.; Kalinka, A. Properties of TiC and TiN Reinforced Alumina-Zirconia Composites Sintered with Spark Plasma Technique. Metals 2019, 9, 1220. [CrossRef]

37. Qiao, Y.; Xu, D.; Wang, S.; Ma, Y.; Chen, J.; Wang, Y.; Zhou, H. Corrosion and Tensile Behaviors of Ti-4Al-2V-1Mo-1Fe and Ti-6Al-4V Titanium Alloys. Metals 2019, 9, 1213. [CrossRef]

38. Krishnamurthy, R.; Bharatiraja, C.; Adedayo, Y.; Tariq, M.; Azeem, A. Locating Wire Fault in Controller Area Network Based on Kelvin (Four-Wire) Resistance Approach BT-Applications of Computing, Automation and Wireless Systems in Electrical Engineering; Mishra, S., Sood, Y.R., Tomar, A., Eds.; Springer: Singapore, 2019; pp. 1129-1139.

39. Kyoung, S.; Jung, E.-S.; Sung, M.Y. Investigation of the layout and optical proximity correction effects to control the trench etching process on $4 \mathrm{H}-\mathrm{SiC}$. Electron. Mater. Lett. 2017, 13, 368-372. [CrossRef]

40. Park, G.-T.; Lee, B.-R.; Son, K.; Park, Y.-B. Ni Barrier Symmetry Effect on Electromigration Failure Mechanism of $\mathrm{Cu} / \mathrm{Sn}-\mathrm{Ag}$ Microbump. Electron. Mater. Lett. 2019, 15, 149-158. [CrossRef] 